\title{
Estandarización de una prueba de ELISA para detectar anticuerpos IgE en pacientes con equinococosis quistica y su utilidad en el diagnóstico y seguimiento de pacientes tratados con albendazol: reporte preliminar
}

Standarization of an ELISA test to detect IgE antibodies in patients with cystic echinococcosis and its use in diagnosis and follow-up of patients treated with albendazol: preliminary report

\author{
Herman Vildózola ${ }^{1}$, Irma Espinoza', William H. Roldan ${ }^{1}$ \\ Instituto de Medicina Tropical Daniel A. Carrión, Facultad de Medicina, Universidad Nacional Mayor de San Marcos.
}

\begin{abstract}
Resumen
Objetivos: Determinar las diluciones y concentraciones optimas de una prueba de ELISA para detectar anticuerpos IgE, así como su sensibilidad, espécificidad y valor predictivo en pacientes con equinococosis quistica. Analizar si los niveles de anticuerpos lgE especificos se correlacionan con la respuesta al tratamiento médico con albendazol en un periodo mayor a un año de finalizado el tratamiento. Diseño: Estudio cuasiexperimental con grupo control. Institución: Instituto de Medicina Tropical Daniel A. Carrión, Facultad de Medicina, UNMSM, Lima, Perú. Material de estudio: Prueba de ELISA para anticuerpo IgE. Intervenciones: Estandarizacion de la prueba de ELISA para anticuerpo IgE y diseño preexperimento con preprueba y posprueba en un solo grupo, para evaluar su valor en el diagnóstico y seguimiento postratamiento de pacientes con quiste hidatidico hepatico tratados con albendazol. Para la estandarizacion de la prueba de ELISA, se utilizó suero de cinco pacientes con diagnóstico clínico de equinococosis quistica, y la sensibilidad y especificidad de la prueba se usó suero de 30 pacientes aparentemente sanos. Para determinar las reacciones cruzadas, se utilizó 16 muestras de suero de pacientes con otras helmintiasis (ascariasis, strongiloidiasis, toxocariosis, trichuriasis, himenolepiasis, cisticercosis y teniasis). Para el diagnóstico y seguimiento postratamiento de equinocococosis quística, se utilizó el suero de 17 pacientes. Principales medidas de resultados: Sensibilidad y especificidad de prueba estandarizada de ELISA para detectar anticuerpos IgE. Resultados: La prueba estandarizada de ELISA para detectar anticuerpos IgE tuvo una sensibilidad de $95,6 \%$ y una especificidad de $100 \%$. En los pacientes con quiste hidatídico hepático considerados curados, uniformemente disminuyeron los niveles de anticuerpo tipo IgE hasta la negativización. Se obtuvo elevación de los niveles de lgE en los pacientes que presentaron recurrencia de la enfermedad quistica hepática. Conclusiones: En el presente estudio se encontró un excelente nivel de sensibilidad y especificidad de la prueba de ELISA para anticuerpos IgE de equinococosis quística. La curación de los quistes coincidió con una dismuinución progresiva de los niveles de lgE, que pudo llegar a la negativización después de un año postratamiento y fue de gran utilidad para detectar la recurrencia. La persistencia de niveles elevados de lgE en pacientes tratados médicamente fue indicativo de no haber respuesta al tratamiento. Siendo no muy grande el tamaño de la muestra de nuestro estudio, es necesario continuar con la investigación para confirmar estos resultados.
\end{abstract}

Palabras clave: ELISA IgE, equinococosis quistica, albendazol.

\section{Abstract}

Objectives: To determine best dilutions and concentrations of ELISA test to detect IgE antibody, its sensitivity and specificity and predictive value in patients with cistyc echinococcosis. To analyze the relationship between IgE specific antibody level and albendazole medical treatment response in a period over one year after completion of albendazole therapy. Design: Quasiexperimental study with control group. Setting: Instituto de Medicina Tropical Daniel A. Carrion, Faculty of Medicine, UNMSM, Lima, Peru. Study material: IgE antibody ELISA test. Interventions: IgE antibody ELISA test standardization with preexperimental pretest and post test in one group to assess its value in diagnosis and post-treatment of patients with hepatic hydatid cysts treated with albendazole. For ELISA test standardization we used serum from five patients with clinical and immunological diagnosis of cystic echinococcosis; to test sensitivity and specificity sera of 30 apparently healthy subjects were studied; to determine crossreactions 16 serum samples from patients with other helminth infections (ascariasis, strongiloidiasis, toxocariasis, trichuriasis, hymenolepiasis cysticercosis and taeniasis) were used. For diagnosis and post-treatment evaluation of cystic echinocococosis serum from 17 patients was studied. Main outcome measures: Standarized ELISA test sensitivity and specificity to detect IgE antibodies. Results: Sensitivity and specificity of standardized ELISA test to detect IgE antibody were respectively $95.6 \%$ and $100 \%$. Patients with hepatic hydatid cyst considered cured uniformly showed lower levels of IgE antibody even to negativization. There was increase of IgE levels in patients who had recurrence of hepatic cystic disease. Conclusions: This study found excellent sensitivity and specificity of ELISA test for cystic echinococcosis IgE antibodies. Healing of cysts coincided with progressive decrease in IgE levels that could reach negativization after one year post-treatment and was useful to detect recurrence. Persistence of IgE high levels in patients treated medically was indicative of no response to treatment. As sample size was not large, it seems necessary to continue investigation to confirm these results.

Key words: IgE ELISA, cystic echinococcosis, albendazole.

An Fac med. 2012;73(1):35-41 


\section{INTRODUCCIÓN}

La equinococosis quística (EQ) causada por larvas de Echinococcus granulosus es una zoonosis parasitaria que constituye un serio problema de salud pública en muchas regiones del mundo ${ }^{(1)}$. Esta enfermedad es usualmente diagnosticada mediante exámenes clínicos con diferentes técnicas de imagen y pruebas inmunológicas para la detección de anticuerpos séricos específicos contra el parásito. La sensibilidad y especificidad de las diferentes pruebas inmunoserológicas dependen de la etapa de la enfermedad, la localización de los parásitos, los antígenos y las técnicas utilizadas ${ }^{(2-4)}$.

El líquido hidatídico de quistes (HCF) de E. granulosus de origen ovino o vacuno constituye una fuente de antígenos que ha sido ampliamente utilizado para el desarrollo de pruebas inmunoserológicas. Con el objetivo de identificar aquellos antígenos del parásito que pudieran ser relevantes para el inmunodiagnóstico de la hidatidosis y proporcionar una prueba inmunoserológica más sensible y específica, diferentes estudios han llevado a la caracterización de dos principales antígenos del HCF, llamados antígeno 5 (Ag5) y el antígeno $\mathrm{B}(\mathrm{AgB})^{(3,4)}$.

El Ag5 es una lipoproteína con peso molecular de 57 y $67 \mathrm{kDa}$ y que bajo condiciones de reducción parece estar compuesta por subunidades de 22 y 38 kDa. Históricamente, el Ag5 ha sido uno de los antígenos más ampliamente utilizados para el inmunodiagnóstico de la EQ. Sin embargo, diferentes estudios han demostrado que el $\mathrm{Ag} 5$ reacciona en forma cruzada con anticuerpos para otros cestodos.

El $\mathrm{AgB}$ es una lipoproteína polimérica de $120 \mathrm{kDa}$ y que bajo condiciones de reducción parece estar compuesto por tres subunidades con tamaños moleculares de 8 a 12,16 y $24 \mathrm{kDa}$. La subunidad más pequeña ha demostrado ser el blanco más útil en los estudios de diagnóstico ${ }^{(5-7)}$. Aunque las evidencias sugieren que el $\mathrm{AgB}$ tiene alto valor diagnóstico, su importancia en el control de la eficacia del tratamiento medico o quirúrgico en la $\mathrm{EQ}$ permanece aún desconocido.

Una serie de informes recientes demuestran el valor potencial que posee el análisis de anticuerpos específicos de las subclases del IgG para serodiagnóstico específico de la EQ o para estudios de seguimiento después de la cirugía o después de la quimioterapia ${ }^{(1,5,7-10)}$. De las subclases de IgG, la subclase IgG4 resultaría ser más específica para el inmunodiagnóstico; pero, aún cuando se pudiera alcanzar alta sensibilidad o especificidad utilizando el líquido hidatídico total o alguno de los antígenos purificados, la detección de estos anticuerpos tiene como principal limitación su incapacidad para correlacionarse en forma positiva con la evolución postoperatoria del paciente o la respuesta al tratamiento médico con albenzadol ${ }^{(4,7-9)}$, y esto constituye un obstáculo para hablar de curación en aquellos casos en que la respuesta aparente al tramiento con albendazol ha sido catalogada como éxito terapéutico: curación (desaparición o calcificación de los quistes) y marcada mejoría (reduccion mayor al 25\% del tamaño del quiste o paso del quiste a CE4 o CE5, según la clasificacion de la OMS). Esta clasificación es muy útil, porque es un esfuerzo para correlacionar los hallazgos ultrasonográficos del quiste hidatídico con su actividad clínica, la cual decrece desde los tipos CE1 y CE2, que son los más activos, al CE5 que representa la lesión parasitaria más inactiva. Sin embargo, en la práctica no siempre es posible encontrar esta concordancia entre la imagen ultrasonográfica y el grado de actividad. En estos casos, el estudio inmunoserológico podría representar el complemento ideal para aclarar si la imagen quística está activa o no.

En ese sentido, algunos autores han encontrado que el dosaje de IgE total sérica o la detección de anticuerpos IgE parecen correlacionarse con la evolución postoperatoria o con la respuesta al tratamiento médico ${ }^{(11-14)}$.
El objetivo del presente estudio fue estandarizar una prueba de ELISA para la detección de anticuerpos IgE, que pudiera ser útil para el diagnóstico inmunológico de la EQ, y permitiera hacer el seguimiento postratamiento quimioterápico con albendazol, así como detectar precozmente las recurrencias postratamiento.

\section{MÉTODOS}

El presente estudio fue cuasiexperimental con grupo control, para la estandarización de la prueba de ELISA para anticuerpos $\operatorname{IgE}$ y diseño prexperimento con preprueba y posprueba en un solo grupo para evaluar su valor en el diagnóstico y seguimiento postratamiento de pacientes con quiste hidatídico hepático tratados con albendazol.

Para la estandarización de la prueba de ELISA-IgE, se utilizó cinco muestras de suero de pacientes con diagnóstico clínico de equinococosis quística y con serología positiva a hidatidosis, mediante las pruebas de ELISA y Western blot (con bandas diagnósticas de 8, 16 y 21 $\mathrm{kDa}$ ). Estos sueros sirvieron para determinar la sensibilidad de la prueba. Para calcular la especificidad de la prueba, se utilizó 30 muestras de suero de individuos aparentemente sanos y con serología negativa a hidatidosis. Para determinar la ocurrencia de reacciones cruzadas de la prueba de ELISA, se usó 16 muestras de suero de pacientes con otras helmintiasis (dos con ascariosis, dos con estrongiloidosis, cuatro con toxocariosis, dos con trichurosis, tres con himenolepiasis, dos con cisticercosis y uno con teniasis).

Asimismo, la prueba de ELISA-IgE fue evaluada en un grupo de pacientes con equinococosis quística con o sin resultado positivo a la prueba de inmunoblot, antes, durante o un tiempo después de finalizado el tratamiento con albendazol.

Para la preparación de los antígenos parasitarios, el líquido hidatídico de quistes (HCF) de E. granulosus fue 
obtenido a partir de quistes hidatídicos pulmonares o hepáticos de origen ovino procedentes de un camal local. El contenido proteico de los antígenos fue realizado según el método de Lowry y colaboradores ${ }^{(16)}$.

El antígeno 5 y el antígeno B (Ag5$\mathrm{AgB}$ ) fueron semipurificados a partir de los antígenos HCF, siguiendo la metodología descrita por Oriol y colaboradores ${ }^{(15)}$. El contenido proteico de los antígenos fue realizado según el método de Lowry y colaboradores ${ }^{(16)}$.

La prueba de ELISA fue estandarizada y desarrollada de acuerdo a los métodos descritos por Roldán y colaboradores ${ }^{(17)}$. Brevemente, placas de poliestireno para microtitulación (96 pocillos de fondo plano) fueron sensibilizados con los antígenos del parásito (HCF o Ag5-AgB) a diferentes concentraciones de 0,5, 1, 5, 10 y $20 \mathrm{ug} / \mathrm{mL}$. Las muestras de suero fueron diluidas a

Tabla 1. Resultados de la prueba de ELISA-IgE.

\begin{tabular}{ccc} 
Sujetos & \multicolumn{2}{c}{ ELISA-lgE } \\
\cline { 2 - 3 } Equinococosis quística (5) & 5 & 0 \\
Ascariosis (2) & 1 & 1 \\
Estrongiloidosis (2) & 0 & 2 \\
Toxocariosis (4) & 1 & 3 \\
Trichurosis (2) & 0 & 2 \\
Himenolepiasis (3) & 0 & 3 \\
Cisticercosis (2) & 0 & 2 \\
Teniasis (1) & 0 & 1 \\
Aparentemente sanos (30) & 0 & 30 \\
\hline Total & 7 & 44 \\
\hline
\end{tabular}

diferentes diluciones $(1 / 5,1 / 10,1 / 20 \mathrm{y}$ 1/40) en búfer fosfato salino (PBS, $\mathrm{pH}$ $=7,2$ ) conteniendo leche descremada al 5\% y Tween 20 al 0,1\% (PBS-lecheTween). Dichas muestras (100 uL/poci1lo) fueron incubadas durante tres horas a $37^{\circ}$ C. Posteriormente, se realizó un ciclo de lavados con PBS-Tween 20 al 0,3\%, en constante agitación durante 5 minutos por cada lavado. Luego, se procedió a agregar el anticuerpo monoclonal anti-IgE humano conjugado con peroxidasa diluida a 1:500 y 1:1000 (100 uL/pocillo) y se incubó

Tabla 2. Pacientes seleccionados para ser evaluados mediante la detección de los niveles de anticuerpos IgE.

\begin{tabular}{|c|c|c|c|c|c|c|c|c|c|c|c|c|}
\hline \multirow{2}{*}{$\mathrm{N}$} & \multirow{2}{*}{ Paciente } & \multirow{2}{*}{ Edad } & \multirow{2}{*}{ Sexo } & \multirow{2}{*}{$\begin{array}{l}\text { Años post- } \\
\text { tratamiento }\end{array}$} & \multirow{2}{*}{$\mathrm{N}^{\circ}$ quistes } & \multicolumn{7}{|c|}{ Muestra $\mathrm{N}^{0}$} \\
\hline & & & & & & $1^{*}$ & 2 & 3 & 4 & 5 & 6 & 7 \\
\hline 1 & $\mathrm{RR}$ & 40 & $\mathrm{~F}$ & 3 & 1 & $x$ & $x$ & $x$ & $x$ & & & \\
\hline 2 & VMA & 77 & M & 3 & 4 & $x$ & $x$ & $x$ & $x$ & $x$ & $x$ & \\
\hline 3 & MM & 53 & $\mathrm{~F}$ & 10 & 1 & $x$ & $x$ & $x$ & & & & \\
\hline 4 & $\mathrm{JC}$ & 73 & $\mathrm{~F}$ & 3 & 2 & $x$ & $x$ & $x$ & & & & \\
\hline 5 & $A B$ & 65 & $\mathrm{~F}$ & 5 & 1 & $x$ & $x$ & $x$ & & & & \\
\hline 6 & RM & 29 & $\mathrm{~F}$ & 6 & múltiples & $x$ & $x$ & $x$ & $x$ & & & \\
\hline 7 & AR & 66 & $\mathrm{~F}$ & 4 & 4 & $x$ & $x$ & $x$ & & & & \\
\hline 8 & CLB & 40 & $\mathrm{~F}$ & 6 & 20 & $x$ & $x$ & & & & & \\
\hline 9 & $\mathrm{FG}$ & 48 & $\mathrm{~F}$ & 1 & múltiples & $x$ & $x$ & & & & & \\
\hline 10 & ER & 69 & $\mathrm{~F}$ & 10 & 3 & $x$ & $x$ & & & & & \\
\hline 11 & JVS & 65 & M & 1 & 1 & $x$ & $x$ & & & & & \\
\hline 12 & MN & 63 & $\mathrm{~F}$ & 2 & 3 & $x$ & $x$ & & & & & \\
\hline 13 & GCV & 38 & $\mathrm{~F}$ & 1 & 2 masas & $x$ & $x$ & $x$ & $x$ & & & \\
\hline 14 & MPR & 59 & $\mathrm{~F}$ & 1 & 1 & $x$ & $x$ & $x$ & $x$ & & & \\
\hline 15 & $\mathrm{FL}$ & 71 & M & 5 & 3 & $x$ & $x$ & $x$ & & & & \\
\hline 16 & $\mathrm{MC}$ & 47 & $\mathrm{~F}$ & 2 & 7 & $x$ & $x$ & & & & & \\
\hline 17 & PET & 54 & $\mathrm{~F}$ & 1 & 1 & $x$ & $x$ & & & & & \\
\hline 18 & MCap & 71 & $\mathrm{~F}$ & 1 & 6 & $x$ & $x$ & & & & & \\
\hline
\end{tabular}

$\mathrm{x}=$ Muestra tomada antes del inicio del tratamiento. 
por una hora a temperatura ambiente. Se realizó un nuevo ciclo de lavados y finalmente se agregó una solución de substrato-cromógeno (OPD y peróxido de hidrógeno en buffer citrato a $\mathrm{pH}=$ $5,0)$ y se incubó a temperatura ambiente por espacio de 30 minutos. La lectura de las placas de ELISA se realizó en un ELISA reader Multiskan plus 2,0, a una longitud de onda de $492 \mathrm{~nm}$.

Con todos los datos obtenidos, se construyó una tabla de 2 × 2 para calcular la sensibilidad, especificidad y los valores predictivos de la prueba de ELISA-IgE. Asimismo, se analizó la utilidad de cada tipo de antígeno utilizado para el desarrollo de la prueba, con el fin de encontrar el antígeno adecuado para la detección de los anticuerpos IgE.

Para la aplicación de la prueba de ELISA estandarizada para detectar IgE en los pacientes antes y por lo menos un año después de concluido el tratamiento con albendazol, se incluyeron 18 pacientes, a los cuales se les realizó la prueba antes y por lo menos una vez más después de un año de finalizado el tratamiento.

\section{RESULTADOS}

La prueba de ELISA-IgE fue estandarizada bajo las siguientes condiciones: la concentración idónea de los antígenos HCF o del Ag5-AgB para la sensibilización de las placas de ELISA fue de $1 \mathrm{ug} /$ $\mathrm{mL}$ por 24 horas, a $4^{\circ} \mathrm{C}$; la dilución óptima del suero fue $1 / 5$ en PBS-leche al $5 \%$, con incubación de 3 horas a $37^{\circ} \mathrm{C}$ y, la dilución óptima del anticuerpo conjugado, 1:500 e incubación de 2 horas a $37^{\circ} \mathrm{C}$. El valor de punto de corte (cutoff) para la prueba de ELISA fue 0,05, a una longitud de onda de $492 \mathrm{~nm}$.

La sensibilidad y la especificidad de la prueba de ELISA-IgE fueron 95,6\% y $100 \%$, respectivamente, establecidas en los cinco pacientes con equinococosis quística y comprobadas con ELISA y Western Blot positivas a las bandas 8, 16,21 , en 30 controles normales y 16 pacientes con otras helmintiasis (tabla $1)$.

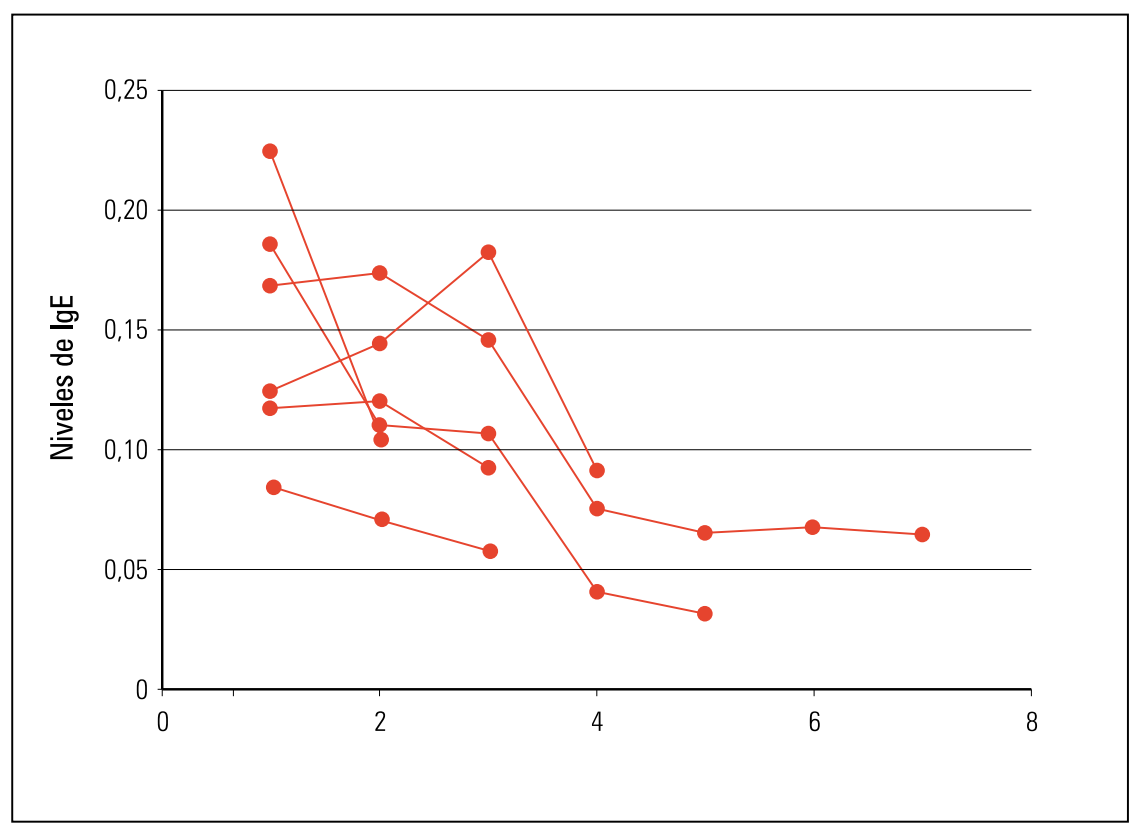

Figura 1. Niveles de anticuerpos IgE en pacientes con equinococosis quística clínicamente curados.
De un total de 18 pacientes -17 con equinococosis quística hepática y uno con equinococosis quística hepática y pulmonar, 15 del sexo femenino y tres del sexo masculino, con edades entre 29 y 77años (promedio 51,1 años)-, seis pacientes presentaron quiste único, un paciente dos quistes, tres pacientes tres quistes, dos con cuatro quistes, uno con seis, uno con siete y cuatro con masas quísticas conteniendo numerosos quistes (más de 10). Una paciente, además de los seis quistes hepáticos, presentó ocho quistes pulmonares, atendidos en

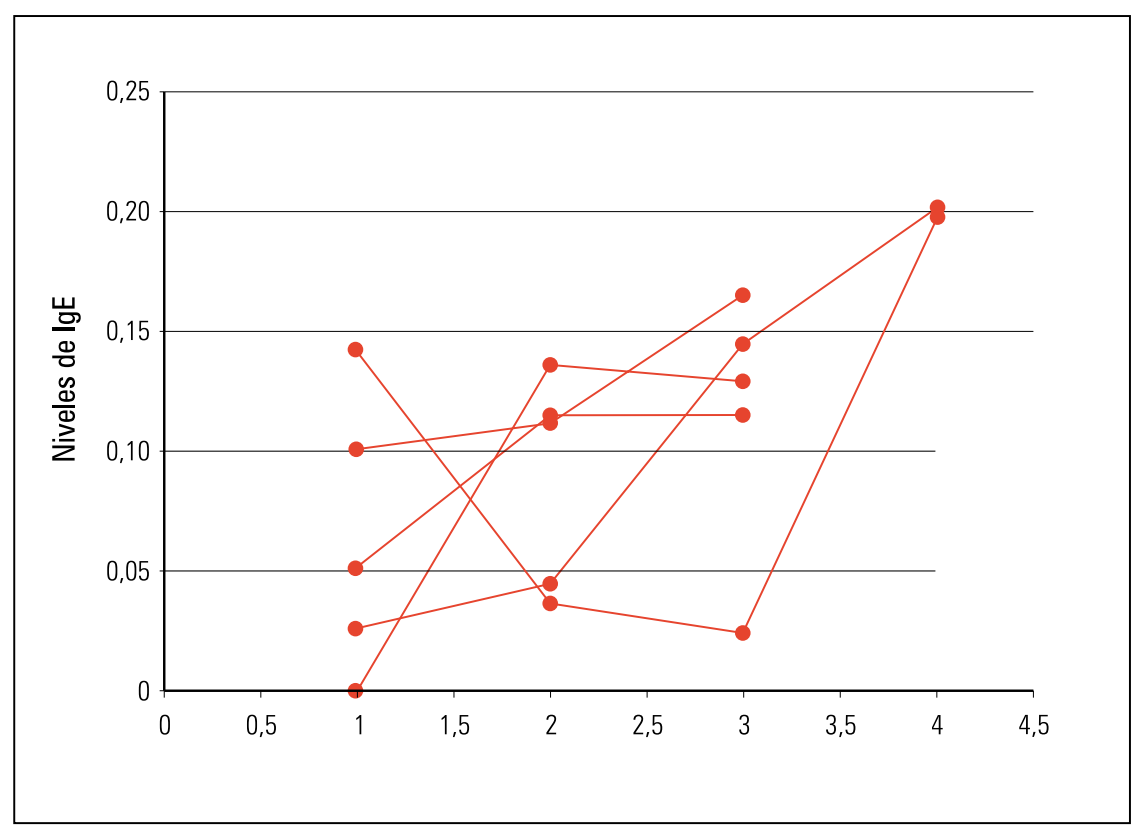

Figura 2. Niveles de anticuerpos IgE en pacientes con equinococosis quística con recurrencia. 


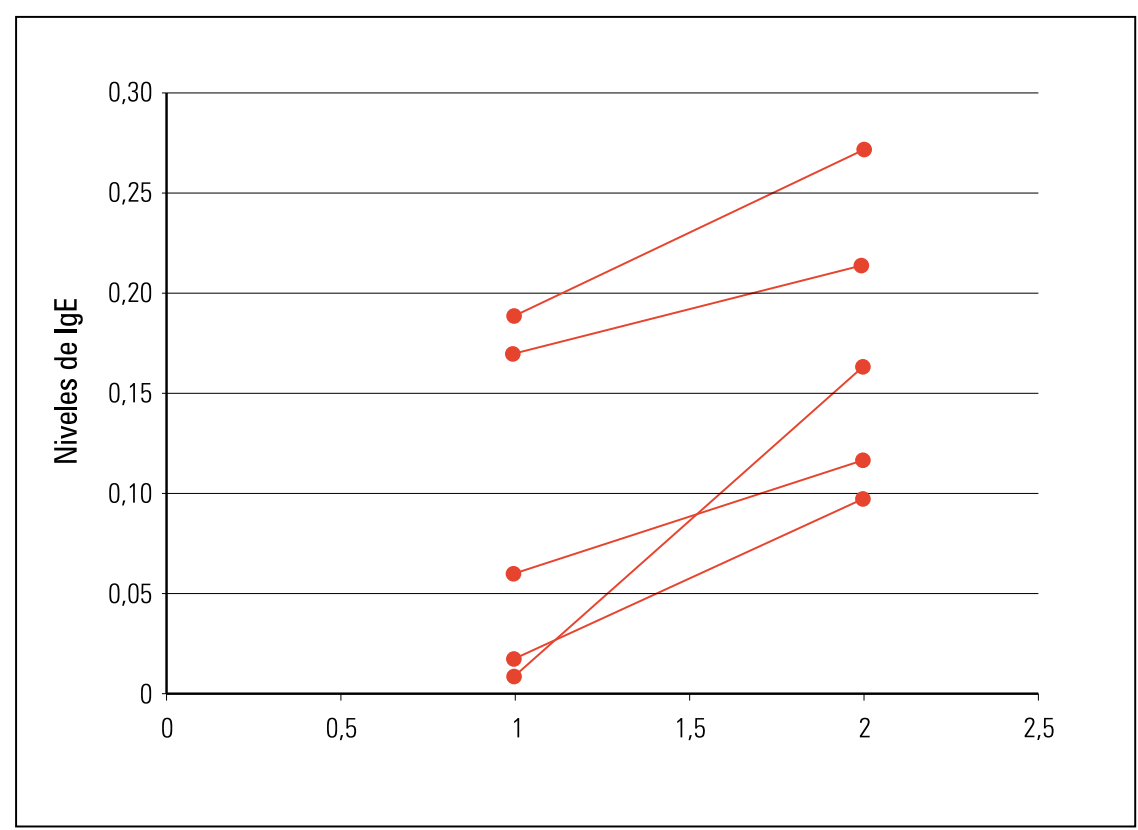

Figura 3. Niveles de anticuerpos IgE en pacientes que no respondieron al tratamiento.

los consultorios externos del Instituto de Medicina Tropical D.A. Carrión, entre los años 2001 y 2010; en ellos se obtuvo por lo menos una muestra antes del inicio del tratamiento con albendazol y una muestra durante o por lo menos un año después de finalizado el tratamiento. Ellos fueron seleccionados para ser evaluados mediante la detección de los niveles de anticuerpos IgE (tabla 2).

Estos 18 pacientes fueron divididos en cuatro grupos; el primer grupo correspondió a los pacientes considerados

clínica y ultrasonográficamente como curados y que incluyó seis pacientes, $33,3 \%$ de la muestra, y que presentó uniformemente reducción significativa de los niveles de IgE (figura 1); en el grupo 2 se incluyó cinco pacientes $(27,7 \%)$, que tuvieron marcada mejoría o curación, pero que en el seguimiento entre uno y 6 años presentaron recurrencia del quiste (figura 2); el grupo 3 incluyó cinco pacientes $(27,7 \%)$ que no respondieron al tratamiento (figura 3); y el grupo 4 estuvo formado por dos pacientes que en octubre de $2011 \mathrm{com}$ pletaron el tercer ciclo de tratamiento; en uno de ellos, la IgE fue negativa antes del tratamiento y se volvió positiva al completar el tercer ciclo, coincidiendo con marcados cambios en la eco estructura de los quistes, pasando de CE1 a CE3, según la clasificación de la OMS (figura 4).

En el grupo 1, la evaluación de anticuerpos $\operatorname{IgE}$ se realizó entre uno y 10 años postratamiento; en el grupo 2, fue entre uno y 6 años; en el grupo 3, entre uno y 10 años; y finalmente en el grupo 4 se tomó las muestras de suero para detectar el anticuerpo IgE al completar el tercer ciclo de tratamiento con albendazol.

\section{DISCUSIÓN}

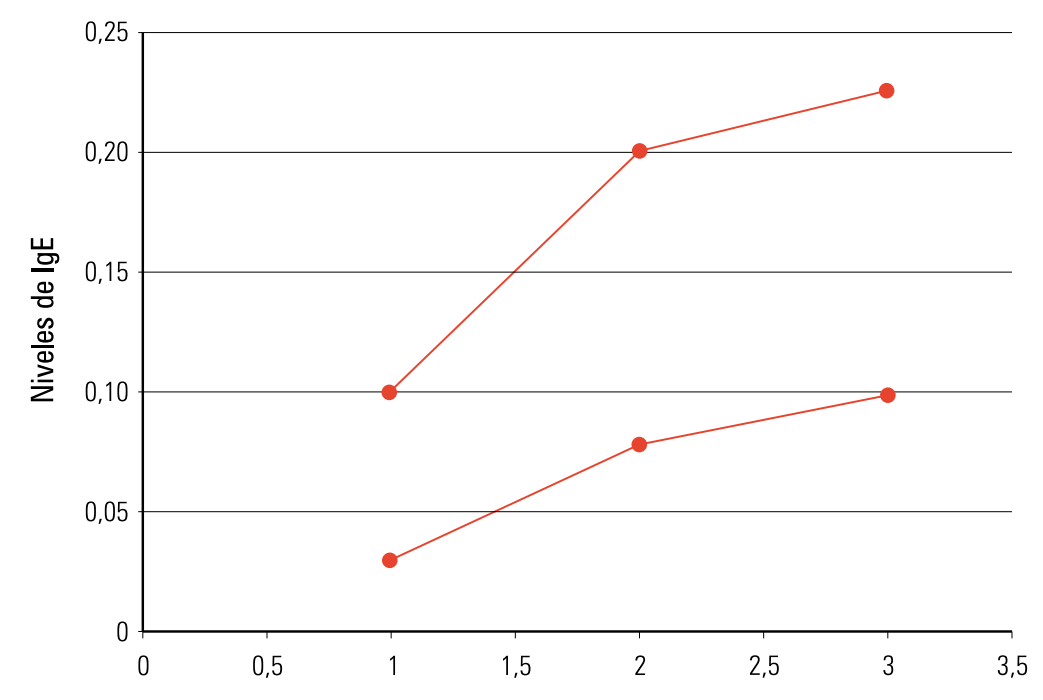

A partir de la clasificación ultrasonográfica del quiste hidatídico hepático, propuesto por la OMS, en $2001^{(17)}$, en el que se establece una correlación de manera práctica de las características de la imagen ecográfica con el grado de actividad del parásito, se han intensificado los estudios para determinar la respuesta al tratamiento médico con benzimidazoles, especialmente con albendazol. Sin embargo, al no existir una perfecta correlación entre la imagen y el estado de viabilidad del quiste, se hace necesario recurrir a procedimientos complementarios, para confirmar si el quiste está activo o no, como podrían ser la pruebas inmunológicas, ahora que están perfectamente definidos los principales antígenos $(\mathrm{Ag} 5$ y $\mathrm{AgB})$ del Figura 4. Niveles de anticuerpos IgE en dos pacientes al final del tratamiento. 
puestas de anticuerpos que podemos determinar con precisión en el suero de los pacientes.

En este sentido, en el presente estudio hemos estandarizado una prueba de ELISA para determinar la IgE, tanto para el diagnóstico como para el seguimiento de los pacientes tratados con albendazol, que ha sido establecido como altamente específico, ya que los niveles de este anticuerpo se redujeron significativamente en el postratamiento, en los pacientes considerados curados o con marcada mejoría, de acuerdo a los cambios ultrasonográficos observados en los diferentes tipos establecidos en la clasificación de la OMS ${ }^{(6,11-13)}$. Al respecto, la prueba de ELISA estandarizada por nosotros presentó $95,6 \%$ de sensibilidad y $100 \%$ de especificidad, al confrontarlo con 30 sueros de personas normales y 16 sueros de pacientes que tenían diagnóstico de otras parasitosis, tanto intestinales como hepáticas, similar a lo encontrado en otros estu$\operatorname{dios}{ }^{(6,11-13)}$.

Un hallazgo importante en este estudio fue comprobar la utilidad de la determinación de IgE para detectar aquellos pacientes que después de haber obtenido una curación ultrasonográfica y también inmunológica, por la negativización de la prueba serológica, se produjo una elevación de los títulos de anticuerpos, coincidiendo con la aparición de imágenes quísticas que, de acuerdo a la clasificación de la OMS, son activos (CE1, CE2). Ello es considerado una recurrencia, como se puede observar en la figura 2, y que en nuestro caso alcanzó $27,7 \%$, porcentaje que está en el rango reportado para diferentes modalidades de tratamiento, y que fluctúa entre $3 \%$ y $30 \%{ }^{(18-23)}$.

Otro hecho observado por nosotros y publicado en la literatura se refiere a los pacientes que inicialmente son negativos a las pruebas inmunológicas y que al recibir uno o más ciclos de tratamiento con albendazol, se positivizan, lo cual observamos también con la prueba de ELISA para IgE y se vio en dos pacientes que inicialmente fueron negativos o positivos débiles y al concluir el segundo ciclo de tratamiento la prueba se hizo fuertemente positiva; esta respuesta tiene su explicación en el mecanismo de acción de albendazol, que inhibe el ensamblaje de la tubulina en los microtúbulos, de modo que altera la absorción de glucosa a través de la capa de células germinativas de la pared del quiste. Esto causa depleción de glicógeno y degeneración del retículo endoplásmico y de las mitocondrias de las células de la capa germinal, que resulta en aumento de los lisosomas y subsecuente muerte celular ${ }^{(24)}$ y produce aumento de la permeabilidad de la membrana quística ${ }^{(25)}$, permitiendo el paso de antígenos hidatídicos al torrente sanguíneo y positivización de las pruebas inmunológicas, en nuestro estudio, de la prueba de IgE.

Referente a los resultados obtenidos en quienes se consideró como curados o con marcada mejoría, se confirmó lo encontrado en la literatura mundial, que luego del tratamiento y respuesta favorable con albendazol, los niveles de IgE descienden progresivamente en los meses o años posteriores, empezando el descenso en algunos casos a los seis meses y negativizándose a partir del año. Esto también lo comprobamos en el presente estudio, en los pacientes que consideramos curados o con marcada mejoría; incluso en pacientes que presentaron recurrencia, también se produjo un descenso significativo de los valores séricos de IgE, como se observa en las figuras 1 y 2 , y que también observaron Manterota y col ${ }^{(13)}$ y Rigano $\mathrm{y} \mathrm{col}^{(6)}$.

Finalmente, los valores de $\operatorname{IgE}$ se mantuvieron elevados en los pacientes que no respondieron al tratamiento, con lo que se comprueba la especificidad de este anticuerpo para detectar la actividad de los quistes, y valora aún más la utilización de este anticuerpo para el seguimiento de los pacientes tratados con albendazol.
Podemos concluir que la prueba de ELISA estandarizada para la detección del anticuerpo IgE es altamente confiable, por su alta sensibilidad $(95,6 \%)$ y especificidad (100\%), confirmado por los resultados obtenidos en los pacientes con quiste hidatídico hepático. La curación de los quistes coincidió con disminución progresiva de los niveles de IgE, que puede llegar a la negativización en los años postratamiento.

La prueba parece ser muy útil para detectar la recurrencia de los casos considerados clínicamente curados. Y la persistencia de niveles elevados de IgE en pacientes tratados es un indicativo de falta de respuesta al tratamiento.

Es necesario continuar la investigación para confirmar estos resultados, en los pacientes de nuestro país.

\section{REFERENCIAS BIBLIOGRÁFICAS}

1. Eckert J, Deplazes P. Biological, epidemiological, and clinical aspects of echinococcosis, a zoonosis of increasing concern. Clin Microbiol Rev. 2004;17(1):107-35.

2. Brunetti $E$, Junghanss T. Update on cystic hydatid disease. Curr Opin Infect Dis. 2009;22(5):497-502.

3. Dziri C, Haouet K, Fingerhut A, Zaouche A. Management of cystic echinococcosis complications and dissemination: where is the evidence? World J Surg. 2009;33(6):1266-73.

4. Stojkovic M, Zwahlen M, Teggi A, Vutova K, Cretu CM, Virdone R, Nicolaidou P, Cobanoglu N, Junghanss $T$. Treatment response of cystic echinococcosis to benzimidazoles: a systematic review. PLoS Negl Trop Dis. 2009;3(9):e524.

5. Aceti A, Pennica A, Teggi A, Fondacaro LM, Caferro M, Leri O, Tacchi G, Celestino D, Quaranta G, De Rosa F, et al. IgG subclasses in human hydatid disease: prominence of the $\lg G 4$ response. Int Arch Allergy Immunol. 1993;102(4):347-51.

6. Riganò R, Profumo E, loppolo S, Notargiacomo S, Ortona E, Teggi A, Siracusano A. Immunological markers indicating the effectiveness of pharmacological treatment in human hydatid disease. Clin Exp Immunol. 1995;102(2): 281-5.

7. Dreweck CM, Lüder CG, Soboslay PT, Kern P. Subclass-specific serological reactivity and lgG4specific antigen recognition in human echinococcosis. Trop Med Int Health. 1997;2(8):779-87.

8. McVie A, Ersfeld K, Rogan MT, Craig PS. Expression and immunological characterization of Echinococcus granulosus recombinant antigen B for IgG4 subclass detection in human cystic echinococcosis. Acta Trop. 1997;67(1-2):19-35.

9. Daeki AO, Craig PS, Shambesh MK. IgG-subclass antibody responses and the natural history of hepatic cystic echinococcosis in asymptomatic patients. Ann Trop Med Parasitol. 2000;94(4):319-28. 
10. Lawn SD, Bligh J, Craig PS, Chiodini PL. Human cystic echinococcosis: evaluation of post-treatment serologic follow-up by lgG subclass antibody detection. Am J Trop Med Hyg. 2004;70(3):329-35.

11. Riganò R, loppolo S, Ortona E, Margutti P, Profumo E, Ali MD, Di Vico B, Teggi A, Siracusano A. Longterm serological evaluation of patients with cystic echinococcosis treated with benzimidazole carbamates. Clin Exp Immunol. 2002;129(3):485-92.

12. Khabiri AR, Bagheri F, Assmar M, Siavashi MR. Analysis of specific lgE and IgG subclass antibodies for diagnosis of Echinococcus granulosus. Parasite Immunol. 2006;28(8):357-66.

13. Manterola C, Vial M, Schneeberger P, Peña JL, Hinostroza J, Sanhueza A. Precision of ELISA-IgE and ELISA-IgG determination in the postoperative follow-up of patients with hepatic echinococcosis. Cir Esp. 2007;81(1):23-7.

14. Lowry OH, Rosebrough NJ, Farr AL, Randall RJ. Protein measurement with the Folin phenol reagent. J Biol Chem. 1951;193(1):265-75.

15. Oriol R, Williams JF, Pérez Esandi MV, Oriol C. Purification of lipoprotein antigens of Echinococcus granulosus from sheep hydatid fluid. Am J Trop Med Hyg. 1971;20(4):569-74.

16. Roldán W, Cornejo W, Espinoza Y. Evaluation of the dot enzyme-linked immunosorbent assay in comparison with standard ELISA for the immunodiagnosis of human toxocariasis. Mem Inst Oswaldo Cruz. 2006;101(1):71-4.

17. WHO Informal Working Group. International classificationof ultrasound images in cystic echinococcosis for application inclinical and field epidemiological setting. Acta Tropica. 2003;85:253-61.

18. Turkyilmaz Z, Sönmez K, Karabulut R, Demirogullari B, Göl H, Basaklar AC, Kale N. Conservative surgery for treatment of hydatyd cysts in children. World $\mathrm{J}$ Surg.2004,28:597-601.

19. Schipper HG, Kager PA. Diagnosis and treatment of hepatic echinococcosis: an overview. Scand J Gastroenterol Suppl. 2004;241:50-5.

20. Atmatzidis KS,Pavlidis TE, Papaziogas BT, Mirelis C, Papaziogas TB. Recurrence and long-term outcome after open cystectomy with omentoplasty for hepatic hydatid disease in an endemic area. Acta Chir Belg. 2005;105:198-202.
21. Smego RA Jr, Sebanego P. Treatment options for hepatic cystic echinococcosis. Int J Infect Dis. 2005;9:69-76

22. Teggi A. An up-to-date on clinical management of human cystic echinococcosis. Parassitologia. 2004;46:405-7.

23. Nahmias J, Goldsmith RS, Soibelman M, el-On J. Three- to 7-year follow-up after albendazole treatment of 68 patients with cystic echinococcosis (hydatid disease). Ann Trop Med Parasitol.1994;88(3):295-304.

24. Kern P. Medical treatment of echinococcosis under the guidance of good clinical practice $(\mathrm{GCP} / \mathrm{ICH})$. Parasitol Internat. 2006;5:S273-S282.

25. Morris DL, Chinnery JB, Georgiou G, Stamatakis G, Golematis B. Penetration of albendazol sulphoxide into hydatid cyst. Gut. 1987;28(1):75-80.

Correspondencia:

Dr. Herman Vildózola

Correo electrónico: vildosola@infonegocio.net.pe 